\title{
Recent Developments in the Application of Borehole Geophysical Logging Techniques in Diamond Mining and Exploration - Some Case Studies
}

\author{
Selfe G.R. ${ }^{1}$, Trofimczyk K.K. ${ }^{1}$
}

1. Anglo American Corporation of South Africa Ltd., Geophysical Services Department, P.O.Box 61587, Marshalltown, Johannesburg, South Africa

Borehole geophysical logging has long been an important tool in the oil exploration industry. It has, however, seldom been as successfully and as quantitatively applied in other divisions of the mining industry. Most often it has been used simply as a horizon delineation tool, with little or no attempt being made at quantification and further interpretation of the results.

The Anglo American Corporation's Geophysical Services Department (AAC GSD) has more recently undertaken extensive research into borehole geophysical logging within the diamond fields in southern Africa with some success. Detailed interpretation of logs and the application of crossborehole tomographic techniques can yield quantitative results and extensively aid the creation of a 3-dimensional model of the orebody. Detailed structural and geotechnical information within the country rock formations can be obtained cost effectively to aid in the planning of the mine pit design.

A number of case studies are presented to illustrate the variety of applications to diamond mining and exploration. These are the evaluation of an alluvial diamond deposit in southern Namibia, the mapping of different kimberlite facies and intrusions at Orapa mine in Botswana, and the mapping of kimberlite types and quantification of country rock assimilation in two diamond prospects in Botswana. Research into cross-borehole tomographic techniques has been undertaken at Venetia mine in South Africa. Methods of determining the geotechnical characteristics of the country rock at Venetia and Orapa mines have also been researched.

Evaluation holes in the Sendelings Drift alluvial diamond deposit in southern Namibia were logged geophysically with a small suite of tools in order to assist mine planning. Neutron and induction logs calibrated using XRD data enabled the delineation of problematic zones of high clay and silt content. In addition, the cementation or hardness index was semi-quantitatively derived using a variety of other $\log$ responses.

Geophysical logging of five core holes and one large-diameter percussion hole at Orapa mine in Botswana succeeded in identifying two types of basalt, and in quantifying their content (percentage ore dilution) within the sidewall. Modal analyses of core samples subsequently confirmed the geophysical interpretations and identified the basalt types as amygdaloidal and non-amygdaloidal varieties respectively. In addition, up to nine different types of kimberlite have been identified and typified in terms of their physical characteristics. These have by and large been linked petrographically to different facies intrusions within both the northern and southern lobes of the Orapa pipe and have helped in resolving ambiguities in the core logging at depth. An example is the confirmation of the presence of a low grade kimberlite breccia derived from the northern lobe which has slumped back into the southern lobe of the deposit. This has implications for the grade model for the southern lobe of the kimberlite.

Geophysical logging was applied on two kimberlite pipes in Botswana as part of the program for evaluating the minable potential of these deposits. These orebodies are very complicated, with multiple intrusions and a great deal of country rock assimilation. In each case, a multidisciplinary approach making use of the detailed geophysical log interpretation, petrographic studies and chip 
logs, was applied in the creation of a detailed 3-dimensional model of the pipe within a short space of time. Subtly different kimberlite types were identified using the geophysical logs, as well as the country rock lithologies. The percentage ore dilution by country rock was also calculated using the geophysical responses. The information supplied by geophysical logging proved important in terms of the understanding of the pipe's genesis and the creation of an accurate mine model.

In order to make a decision on the optimum depth of an open pit kimberlite mine good information on the shape and grade of the kimberlite pipe as well as any structures in the host rock is required. Extensive research into developing a technique for delineating the shape of a kimberlite pipe with depth has been undertaken. The main focus of the project was the Venetia pipe in the Northern Province of South Africa. The initial work involved the establishment of a detailed physical property database. This was accomplished through down-hole geophysical logging in boreholes across the deposit. Based on the physical characteristics measured a number of surface and crosshole scanning techniques were proposed for trial. Borehole seismic methods show greatest potential due to a greater range of operation. Borehole electromagnetic methods, although providing some success towards solving the problem, suffer from lack of penetration within kimberlite which may be very conductive.

Geophysical logging of two country rock boreholes at Venetia mine and one at Orapa mine to measure the geotechnical characteristics of the country rock has indicated the potential of such techniques in providing structural information of use in the engineering design of an open cast diamond mine. The Slimline Accoustic Scanner in conjunction with the Dipmeter probe is able to identify joints and fractures and to classify these in terms of their orientation. The conventional lithological logs offer a means of differentiating between fractures and joints once identified. A combination of the density and P- and S-wave sonic data provides a continuous down-hole estimate of the bulk geotechnical rock parameters, namely, Poisson's ratio, bulk modulus, Young's modulus and shear modulus.

In the above cases quantitative methods are applied in a relatively short space of time, to provide the geologist with information which otherwise may only have been obtained through an extensive core drilling program which is expensive and time consuming. Wireline logging methods are not only capable of uniquely identifying the various lithological components of the wallrock, but also of accurately quantifying these components in a process of calibration and log unmixing. Crossborehole tomography can provide a continuous map of the orebody boundary with depth where otherwise only a single intersection at depth from an inclined hole through the contact would have been available. 